\title{
Effect of Tubular Chiralities and Diameters of Single Carbon Nanotubes on Gas Sensing Behavior: A DFT Analysis
}

\author{
A. A. EL-Barbary ${ }^{1,2^{*}}$, Kh. M. Eid ${ }^{1,3}$, M. A. Kamel11, H. M. Osman1, G. H. Ismail1,2 \\ ${ }^{1}$ Physics Department, Faculty of Education, Ain Shams University, Cairo, Egypt \\ ${ }^{2}$ Physics Department, Faculty of Science, Jazan University, Jazan, KSA \\ ${ }^{3}$ Bukairiayh for Science, Qassim University, Buraydah, KSA \\ Email: ${ }^{*}$ ahla eg@yahoo.co.uk
}

Received 13 January 2014; revised 12 February 2014; accepted 11 March 2014

Copyright @ 2014 by authors and Scientific Research Publishing Inc.

This work is licensed under the Creative Commons Attribution International License (CC BY). http://creativecommons.org/licenses/by/4.0/

(c) (i) Open Access

\begin{abstract}
Using density functional theory, the adsorption of $\mathrm{CO}, \mathrm{CO}_{2}, \mathrm{NO}$ and $\mathrm{CO}_{2}$ gas molecules on different chiralities and diameters of single carbon nanotubes is investigated in terms of energetic, electronic properties and surface reactivity. We found that the adsorption of $\mathrm{CO}$ and $\mathrm{CO}_{2}$ gas molecules is dependent on the chiralities and diameters of CNTs and it is vice versa for $\mathrm{NO}^{2}$ and $\mathrm{NO}_{2}$ gas molecules. Also, the electronic character of CNTs is not affected by the adsorption of $\mathrm{CO}$ and $\mathrm{CO}_{2}$ gas molecules while it is strongly affected by $\mathrm{NO}$ and $\mathrm{NO}_{2}$ gas molecules. In addition, it is found that the dipole moments of zig-zag CNTs are always higher than the arm-chair CNTs. Therefore, we conclude that the zig-zag carbon nanotubes are more preferred as gas sensors than the arm-chair carbon nanotubes, especially for detecting $\mathrm{NO}$ and $\mathrm{NO}_{2}$ gas molecules.
\end{abstract}

\section{Keywords}

\section{Carbon Nanotubes, DFT, Gas Sensors}

\section{Introduction}

Monitoring of combustible gas alarms, gas leak detection, and environmental pollution is of great concern in public security. Advances in nanotechnology give great promise for achieving new sensing materials. Since the discovery of carbon nanotubes in 1991, the single-walled carbon nanotubes (SWCNTs) have been intensively investigated as nanoscale gas sensors because of their great surface areas to bulk ratio and their abilities to mod-

*Corresponding author.

How to cite this paper: EL-Barbary, A.A., Eid, Kh.M., Kamel, M.A., Osman, H.M. and Ismail, G.H. (2014) Effect of Tubular Chiralities and Diameters of Single Carbon Nanotubes on Gas Sensing Behavior: A DFT Analysis. Journal of Surface Engineered Materials and Advanced Technology, 4, 66-74. http://dx.doi.org/10.4236/isemat.2014.42010 
ulate electrical properties upon adsorption of various kinds of gas molecules [1]-[17]. The emission of carbon and nitrogen oxides ( $\mathrm{CO}, \mathrm{CO}_{2}$, $\mathrm{NO}$ and $\mathrm{NO}_{2}$ ) results from the combustion of fossil fuels, contributing to both smog and acid precipitation, and affecting both terrestrial and aquatic ecosystems [18]. Although many efforts have been made to use catalysts to reduce the amount of carbon or nitrogen oxides in the air [19]-[25], an efficient method of sensing and removing carbon and nitrogen oxides is still required.

Because carbon and nitrogen oxides are the most dangerous air pollutants, toxic and global warming gases, our work is concentrated on investigating the effect of tubular chiralities and diameters of single carbon nanotubes on gas sensing behavior for $\mathrm{CO}, \mathrm{CO}_{2}, \mathrm{NO}$ and $\mathrm{NO}_{2}$ gas molecules, applying the first principle calculations.

\section{Computational Methods}

All calculations were performed with the density functional theory as implemented within G03W package [26][29], using B3LYP exchange-functional and applying basis set 6 - 31g (d,p). Pure carbon nanotubes $(5,0)$ and $(9,0),(5,5)$ and $(6,6)$ are fully optimized with spin average as well as the adsorption of $\mathrm{CO}, \mathrm{CO}_{2}$, $\mathrm{NO}$ and $\mathrm{NO}_{2}$ gas molecules.

The obtained diameters [30] and the adsorption energies of gas molecules on CNTs $\left(E_{a d s}\right)$ [31] are calculated from the following relations:

$$
D=0.73\left(n^{2}+n m+m^{2}\right)^{1 / 2}
$$

where $n$ and $m$ are integral numbers, the composition of chiral vector.

$$
E_{\text {ads }}=E_{\text {(nanotube+gas molecules) }}-E_{\text {nanotube }}-E_{\text {gas molecules }}
$$

where $E_{\text {(nanotube+gas molecules) }}$ is the total energy of nanotube and gas molecules, $E_{\text {nanotube }}$ is the energy of the carbon nanotube, and $E_{\text {gas molecules }}$ is the energy of gas molecules.

\section{Results and Discussion}

We will investigate the adsorption of gas molecules, $\mathrm{CO}, \mathrm{CO}_{2}$, $\mathrm{NO}$ and $\mathrm{NO}_{2}$ on four carbon nanotubes with different charilities and diameters $(5,0) \mathrm{CNT},(9,0) \mathrm{CNT},(5,5) \mathrm{CNT}$ and $(6,6) \mathrm{CNT}$ as shown in Figure 1 and Table 1.

\subsection{Adsorption of $\mathrm{CO}, \mathrm{CO}_{2}, \mathrm{NO}$ and $\mathrm{NO}_{2}$ Gas Molecules on CNTs}

We have adsorbed $\mathrm{CO}$ and $\mathrm{CO}_{2}$ gas molecules vertically on different three positions of $(5,0),(9,0),(5,5)$ and $(6,6)$ CNTs: above a carbon atom (carbon site), above a bond between two carbon atoms (bond site) and above a center of a hexagon ring (vacant site). The calculated adsorption energies of $\mathrm{CO}$ and $\mathrm{CO}_{2}$ gas molecules

$(5,0) C N T$

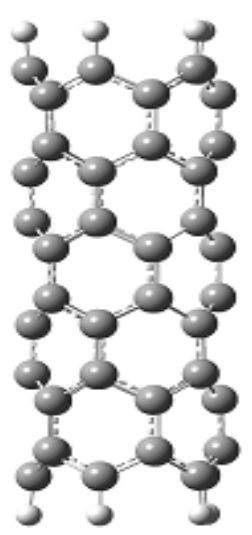

$(9,0) C N T$

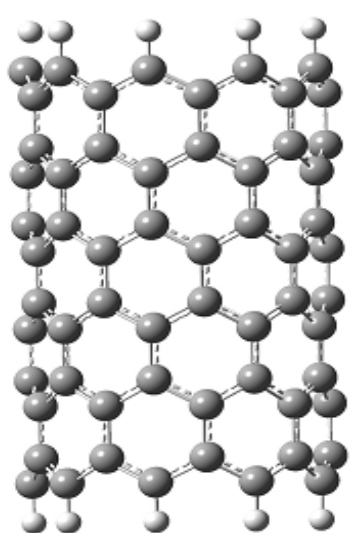

$(5,5) C N T$

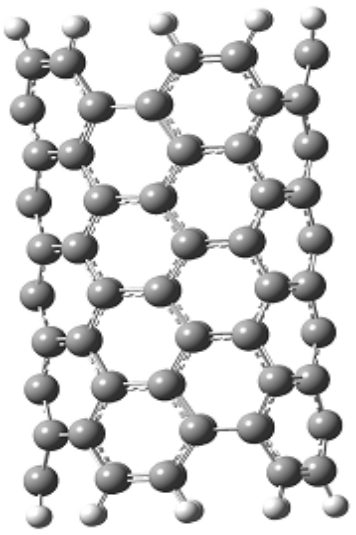

$(6,6) C N T$

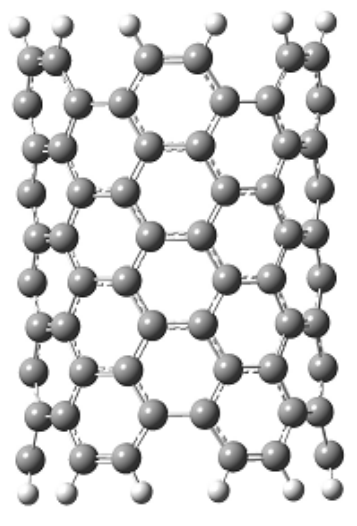

Figure 1 . The fully optimized structures of $(5,0),(9,0),(5,5)$ and $(6,6)$ CNTs. Carbon atoms (gray) and hydrogen atoms (white). 
are listed in Table 2. It is found that the best position and adsorption energy for $\mathrm{CO}$ gas molecule is above the bond site on $(9,0)$ CNT with adsorption energy of $-0.43 \mathrm{eV}$, however for $\mathrm{CO}_{2}$ gas molecule is above the vacant site on $(9,0)$ CNT with adsorption energy of $-0.26 \mathrm{eV}$. Therefore, one can conclude that the best CNT gas sensor for $\mathrm{CO}$ and $\mathrm{CO}_{2}$ gas molecules is the $(9,0) \mathrm{CNT}$.

Also, we have adsorbed $\mathrm{NO}$ and $\mathrm{NO}_{2}$ gas molecules vertically on different three positions of $(5,0),(9,0)$, $(5,5)$ and $(6,6)$ CNTs: above a carbon site, above a bond site and above a vacant site. The calculated adsorption energies of $\mathrm{NO}$ and $\mathrm{NO}_{2}$ gas molecules are listed in Table 3. It is found that the best adsorption energies of NO gas molecule are on the $(9,0)$ CNT above a bond site, then above a carbon site and after that above a vacant site with adsorption energies of $-1.65 \mathrm{eV},-1.55 \mathrm{eV}$ and $-1.34 \mathrm{eV}$, respectively. However, for $\mathrm{NO}_{2}$ gas molecule is found to be above the bond site on $(9,0)$ CNT with adsorption energy of $-1.75 \mathrm{eV}$. Also, it is noticed that the vacant site is always preferred for $\mathrm{NO}_{2}$ gas adsorption on all the studied CNTs except for $(9,0)$ CNT. Therefore, one can conclude that all CNTs can be used as gas sensors for $\mathrm{NO}$ and $\mathrm{NO}_{2}$ gas molecules.

From Table 2, Table 3, one can investigate the effect of the chiralities and the diameters on the CNT gas sensors behavior. It is clear that the adsorption of $\mathrm{CO}$ and $\mathrm{CO}_{2}$ gas molecules is dependent on the chiralities and the diameters of CNTs. The adsorption of $\mathrm{CO}$ and $\mathrm{CO}_{2}$ gas molecules is enhanced with increasing the diameter of the zig-zag CNTs. However, the adsorption of $\mathrm{NO}$ and $\mathrm{NO}_{2}$ gas molecules is independent on the chiralities and the diameters of CNTs.

\subsection{Energy Gaps of Adsorbed $\mathrm{CO}, \mathrm{CO}_{2}, \mathrm{NO}$ and $\mathrm{NO}_{2}$ Gas Molecules on CNTs}

From Table 4, it is clear that the adsorption of $\mathrm{CO}$ and $\mathrm{CO}_{2}$ gas molecules on CNTs does not affect the elec-

Table 1. The configuration structures and diameters of the studied CNTs.

\begin{tabular}{|c|c|c|}
\hline System & Configuration Structures & Diameters/Å \\
\hline$(5,0) \quad \mathrm{CNT}$ & $\mathrm{C}_{60} \mathrm{H}_{10}$ & 3.65 \\
\hline$(9,0) \quad \mathrm{CNT}$ & $\mathrm{C}_{108} \mathrm{H}_{18}$ & 6.57 \\
\hline$(5,5) \quad \mathrm{CNT}$ & $\mathrm{C}_{100} \mathrm{H}_{20}$ & 6.32 \\
\hline$(6,6) \quad \mathrm{CNT}$ & $\mathrm{C}_{120} \mathrm{H}_{24}$ & 7.59 \\
\hline
\end{tabular}

Table 2. The calculated adsorption energies $\left(\boldsymbol{E}_{\text {ads }}\right)$ of $\mathrm{CO}$ and $\mathrm{CO}_{2}$ above a carbon site, a bond site and a vacant site of pristine $(5,0),(9,0),(5,5)$ and $(6,6)$ CNTs. All energies are given by $\mathrm{eV}$.

\begin{tabular}{|c|c|c|c|c|c|c|}
\hline \multirow[b]{2}{*}{ System } & \multicolumn{3}{|c|}{$\mathrm{CO}$} & \multicolumn{3}{|c|}{$\mathrm{CO}_{2}$} \\
\hline & Carbon site & Bond site & Vacant site & Carbon site & Bond Site & Vacant Site \\
\hline$(5,0) \quad \mathrm{CNT}$ & 0.04 & -0.00 & -0.04 & -0.00 & 0.00 & 0.00 \\
\hline$(9,0) \quad \mathrm{CNT}$ & 0.03 & -0.43 & -0.24 & -0.23 & -0.00 & -0.26 \\
\hline$(5,5) \quad \mathrm{CNT}$ & 0.04 & 0.04 & 0.04 & 0.13 & 0.003 & 2.19 \\
\hline$(6,6) \quad \mathrm{CNT}$ & -0.01 & -0.01 & -0.03 & -0.00 & -0.00 & -0.16 \\
\hline
\end{tabular}

Table 3. The calculated adsorption energies $\left(\boldsymbol{E}_{\text {ads }}\right)$ of $\mathrm{NO}$ and $\mathrm{NO}_{2}$ above a carbon site, a bond site and a vacant site of pristine $(5,0),(9,0),(5,5)$ and $(6,6)$ CNTs. All energies are given by $\mathrm{eV}$.

\begin{tabular}{ccccccc}
\hline \multicolumn{1}{c}{ NO } & \multicolumn{2}{c}{$\mathrm{NO}_{2}$} \\
\hline \multicolumn{1}{c}{ System } & Carbon site & Bond site & Vacant site & Carbon Site & Bond site & Vacant site \\
\hline$(5,0)$ CNT & -0.35 & -0.34 & 0.29 & 0.07 & -0.36 & -1.04 \\
$(9,0)$ CNT & -1.55 & -1.65 & -1.34 & -1.19 & -1.75 & -1.40 \\
$(5,5)$ CNT & 0.06 & 0.22 & 0.07 & 2.26 & 0.92 & -1.32 \\
$(6,6)$ CNT & -0.01 & 0.25 & 0.07 & 0.06 & 0.35 & -1.34 \\
\hline
\end{tabular}


tronic character of the CNTs. Also, the band gaps of pristine CNTs and the adsorbed $\mathrm{CO}$ and $\mathrm{CO}_{2}$ gas molecules on CNTs are so close.

From Table 5, the adsorption of $\mathrm{NO}$ and $\mathrm{NO}_{2}$ gas molecules on CNTs is strongly affected the electronic character of the $(9,0)$ and $(5,0)$ CNTs. However, there is not any change of the electronic character for $(5,5)$ and $(6,6)$ CNTs. The band gap of pristine $(5,0) \mathrm{CNT}$ is increased from $0.70 \mathrm{eV}$ to $1.61 \mathrm{eV}$ and to $1.37 \mathrm{eV}$ when $\mathrm{NO}$ and $\mathrm{NO}_{2}$ gas molecules are adsorbed on it, respectively. Also, The band gap of pristine $(9,0) \mathrm{CNT}$ is increased from $0.25 \mathrm{eV}$ to $1.34 \mathrm{eV}$ and to $1.25 \mathrm{eV}$ when $\mathrm{NO}$ and $\mathrm{NO}_{2}$ gas molecules are adsorbed on it, respectively. One can conclude that the electronic character of $(5,0),(9,0),(5,5)$ and $(6,6)$ CNTs is not affected by the adsorption of $\mathrm{CO}$ and $\mathrm{CO}_{2}$ gas molecules. The adsorption of $\mathrm{NO}$ and $\mathrm{NO}_{2}$ gas molecules on CNTs is only strongly affected the electronic character of the $(9,0)$ and $(5,0)$ CNTs, however the $(5,5)$ and $(6,6)$ CNTs are not affected at all.

\subsection{HOMO-LUMO Orbitals of Adsorbing CO, $\mathrm{CO}_{2}$, $\mathrm{NO}$ and $\mathrm{NO}_{2}$ Gas Molecules on CNTs}

Our calculated band gaps show that the adsorption of $\mathrm{CO}$ and $\mathrm{CO}_{2}$ gas molecules on CNTs is not affected the band gaps of the pristine CNTs, however the adsorption of $\mathrm{NO}$ and $\mathrm{NO}_{2}$ gas molecules is strongly affected the band gaps. To explain that the molecular orbitals of adsorbing $\mathrm{CO}, \mathrm{CO}_{2}, \mathrm{NO}$ and $\mathrm{NO}_{2}$ gas molecules on $(5,0)$, $(9,0),(5,5)$ and $(6,6)$ CNTs are investigated, see Figure 2, Figure 3. The band gaps of the pristine CNTs are calculated and are listed in Table 4. The HOMO and LUMO energy orbitals for pristine $(5,0),(9,0)$, $(5,5)$ and $(6,6)$ CNTs are found to be $(-4.13 \mathrm{eV},-3.42 \mathrm{eV}),(-3.93 \mathrm{eV},-3.68 \mathrm{eV}),(-4.62 \mathrm{eV},-2.82 \mathrm{eV})$ and $(-4.70 \mathrm{eV},-2.82 \mathrm{eV})$, respectively. Comparing the HOMO-LUMO energies of the pristine CNTs with ones after the adsorption of $\mathrm{CO}$ and $\mathrm{CO}_{2}$ gas molecules, it is clear that the energy values are so close. Also, it is noticed that there is not any contribution from the gas molecules at the molecular orbitals and the electron density of HOMO and LUMO is distributed over all the carbon atoms of CNTs except for $(9,0)$ CNT is located at the terminals of the tube, see Figure 2. Comparing the HOMO-LUMO energies of the pristine CNTs with ones after the adsorption of $\mathrm{NO}$ and $\mathrm{NO}_{2}$ gas molecules, it is clear that the energy values are so close in case of $(5,5)$ and $(6,6)$ CNTs and are quite far in case of $(5,0)$ and $(9,0)$ CNTs. The HOMO energy levels in case of $(5,0)$ and $(9,0)$ CNTs after adsorbing $\mathrm{NO}$ and $\mathrm{NO}_{2}$ gas molecular are getting deep (lower) in energy however the LUMO energy levels are getting higher in energy. Results in increasing the band gap from $0.70 \mathrm{eV}$ to $1.81 \mathrm{eV}$ in

Table 4. The calculated energy gaps $\left(\boldsymbol{E}_{\mathbf{g}}\right)$ of $\mathrm{CO}$ and $\mathrm{CO}_{2}$ above a carbon site, a bond site and a vacant site of pristine $(5,0)$, $(9,0),(5,5)$ and $(6,6)$ CNTs. All energies are given by eV.

\begin{tabular}{cccccccc}
\hline \multicolumn{1}{c}{} & \multicolumn{3}{c}{$\mathrm{CO}$} \\
\multicolumn{1}{c}{ System } & Pristine CNTs & Carbon site & Bond site & Vacant site & Carbon Site & Bond site & Vacant Site \\
\hline$(5,0)$ CNT & 0.70 & 0.61 & 0.70 & 0.70 & 0.61 & 0.61 & 0.60 \\
$(9,0)$ CNT & 0.25 & 0.25 & 0.25 & 0.25 & 0.25 & 0.24 & 0.25 \\
$(5,5)$ CNT & 1.79 & 1.80 & 1.79 & 1.80 & 1.80 & 1.79 & 1.75 \\
$(6,6)$ CNT & 1.90 & 1.92 & 1.92 & 1.92 & 1.92 & 1.92 & 1.92 \\
\hline
\end{tabular}

Table 5. The calculated energy gaps $\left(\boldsymbol{E}_{\mathbf{g}}\right)$ of $\mathrm{NO}$ and $\mathrm{NO}_{2}$ above a carbon site, a bond site and a vacant site of pristine $(5,0)$, $(9,0),(5,5)$ and $(6,6)$ CNTs. All energies are given by eV.

\begin{tabular}{|c|c|c|c|c|c|c|}
\hline \multirow[b]{2}{*}{ system } & \multicolumn{3}{|c|}{ NO } & \multicolumn{3}{|c|}{$\mathrm{NO}_{2}$} \\
\hline & Carbon site & Bond Site & Vacant Site & Carbon site & Bond Site & Vacant site \\
\hline$(5,0) \quad \mathrm{CNT}$ & 1.61 & 0.99 & 0.94 & 0.61 & 0.99 & 1.37 \\
\hline$(9,0) \quad \mathrm{CNT}$ & 1.34 & 1.24 & 1.14 & 1.25 & 1.25 & 1.14 \\
\hline$(5,5) \quad \mathrm{CNT}$ & 1.79 & 1.81 & 1.79 & 1.72 & 1.76 & 1.79 \\
\hline$(6,6) \quad \mathrm{CNT}$ & 1.92 & 1.90 & 1.92 & 1.94 & 1.88 & 1.91 \\
\hline
\end{tabular}


CO

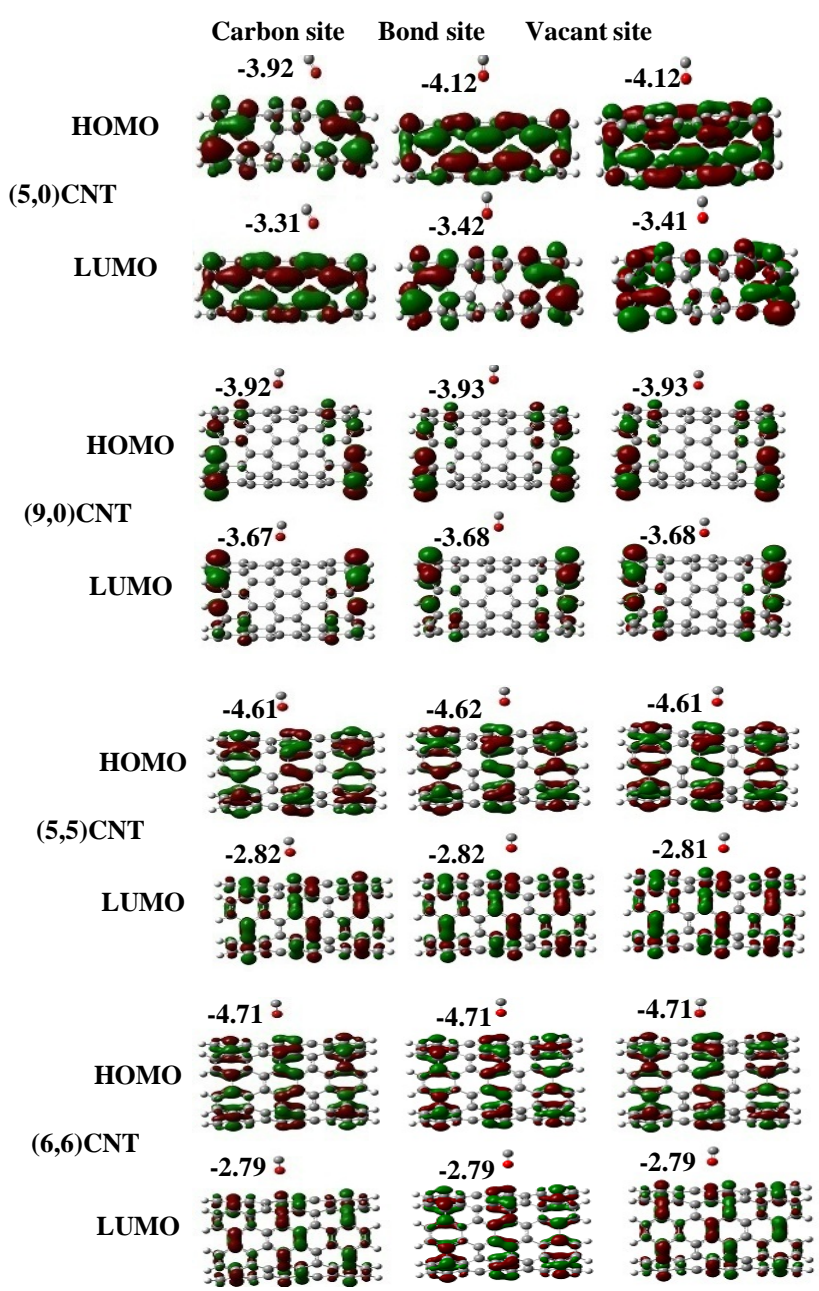

$\mathrm{CO}_{2}$

Carbon site Bond site Vacant site

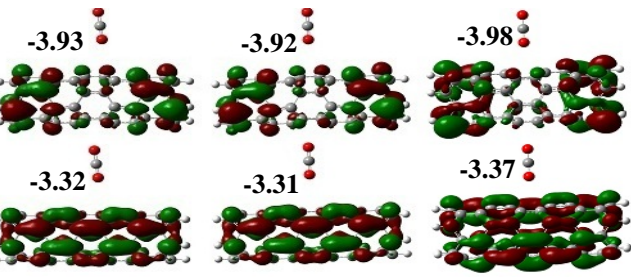

$-3.92:$

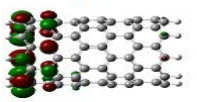

$-3.91:$

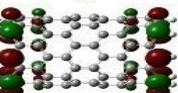

$-3.92:$

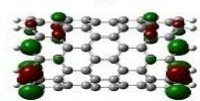

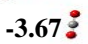

-3.66 :

-3.67 :

.

33538
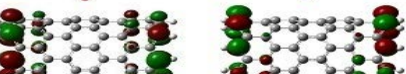

$-4.60 \%$

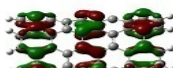

$-4.61 \%$

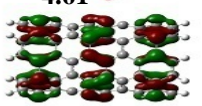

$-2.82^{\circ}$

$-2.82^{\circ}$

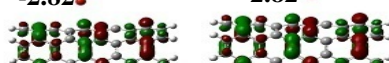

- 8 8.

$-4.55:$
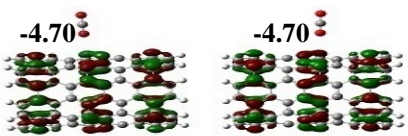

$-4.70$

$: 3: \frac{2}{3}$

$-2.78$

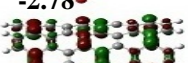

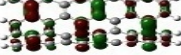

$-2.78$

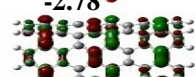

g.

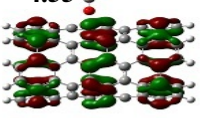

-2.80 :

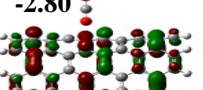

9898:

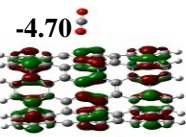

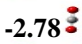

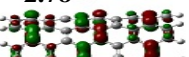

8

Figure 2. HOMO and LUMO molecular orbitals of adsorbing $\mathrm{CO}$ and $\mathrm{CO}_{2}$ gas molecules on the pristine $(5,0),(9,0)$, $(5,5)$ and $(6,6)$ CNTs. Energies of HOMO and LUMO are listed above the molecular orbitals and are given by $\mathrm{eV}$.

case of $(5,0)$ CNT and from $0.25 \mathrm{eV}$ to $1.34 \mathrm{eV}$ in case of $(9,0)$ CNT. Also, it is noticed that there is representation from the NO gas molecule at LUMO of $(9,0)$ and $(6,6)$ CNTs, see Figure 3.

\subsection{The Reactivity of CNT Surfaces before and after Adsorbing Gas Molecules}

Our calculated band gaps and molecular orbitals show that the adsorption of $\mathrm{CO}$ and $\mathrm{CO}_{2}$ gas molecules on CNTs is not affected neither the band gaps nor the molecular orbitals of the pristine CNTs but the adsorption of $\mathrm{NO}$ and $\mathrm{NO}_{2}$ gas molecules is strongly affected both of the band gaps and the molecular orbitals of $(5,0)$ and $(9,0)$ CNTs. To clear that the reactivity of CNT surfaces before and after adsorbing $\mathrm{CO}, \mathrm{CO}_{2}, \mathrm{NO}$ and $\mathrm{NO}_{2}$ gas molecules on $(5,0),(9,0),(5,5)$ and $(6,6)$ CNTs are studied, see Table 6 , Table 7 . The surface reactivity of the pristine CNTs is calculated and is listed in Table 6 . The dipole moments of pristine $(5,0),(9,0),(5,5)$ and $(6,6)$ CNTs are found to be 0.54 Debye, 0.20 Debye 0.00 Debye and 0.00 Debye, respectively.

Comparing the dipole moments of the pristine CNTs with ones that are adsorbed the $\mathrm{CO}$ and $\mathrm{CO}_{2}$ gas molecules, it is clear that the dipole moment values are so close in case of the adsorption of the CO gas molecule but they are higher in case of the adsorption of the $\mathrm{CO}_{2}$ gas molecule, see Table 6. Also, it is noticed that the highest dipole moments after the adsorption of the $\mathrm{CO}_{2}$ gas molecule are 0.74 Debye (when $\mathrm{CO}_{2}$ is adsorbed above the bond site of $(9,0) \mathrm{CNT}$ ) and 0.77 Debye (when $\mathrm{CO}_{2}$ is adsorbed above the vacant site of $(5,5) \mathrm{CNT}$ ), re- 
NO

$$
\text { Carbon site Bond site Vacant site }
$$$$
-4.42 \%-4.37 \& \text { \& }-4.30 \text { : }
$$

HOMO

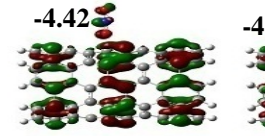

$(5,0)$ CNT

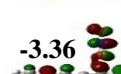

LUMO $\begin{aligned} & -3.36 \\ & \text { He }\end{aligned}$
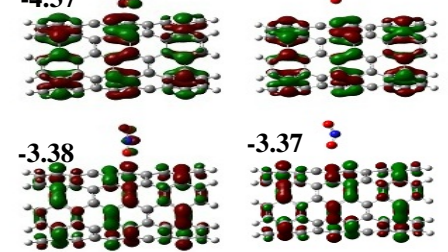

$-3.37:$

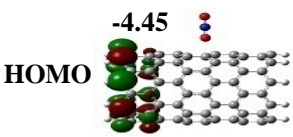

$(9,0)$ CNT

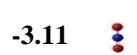

LUMO

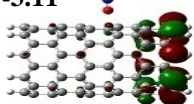

$-4.39:$

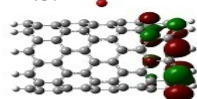

ษ⿻ำ

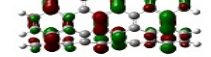

\section{$-4.37:$}
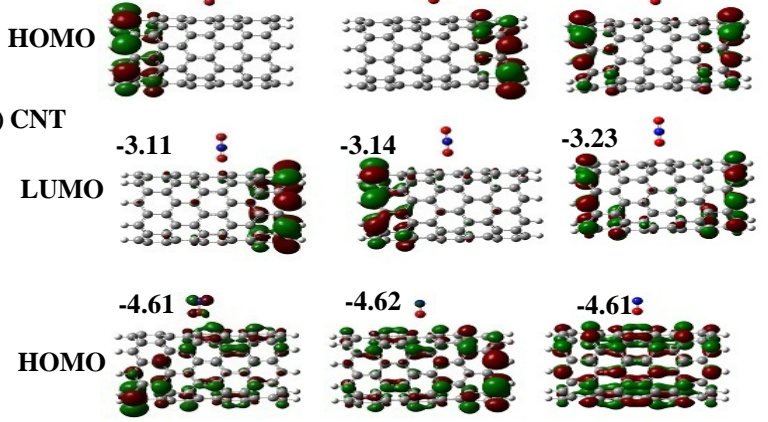

-4.62 :
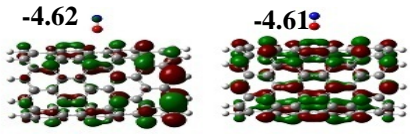

$(5,5)$ CNT

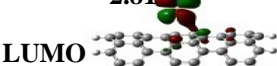

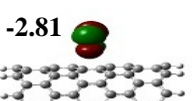

$-2.82$

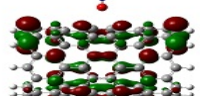

:

2505

-4.71 :

$-4.718$

:79
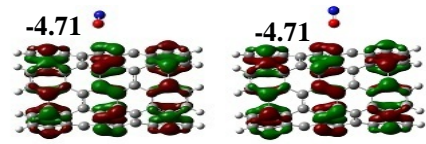

$-3.01^{2}$

-2.79 :

(6,6) CNT -2.79 :

LUMO

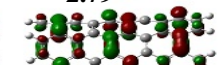

$\mathrm{NO}_{2}$

Carbon site Bond site Vacant site

$-3.93:$

$-4.38:$

$-4.73:$

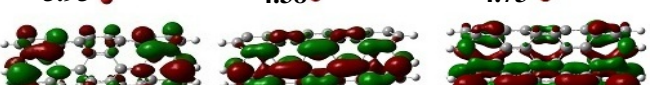
$38 \% 38$ $-3.32:$

$-3.38:$ $-3.36:$
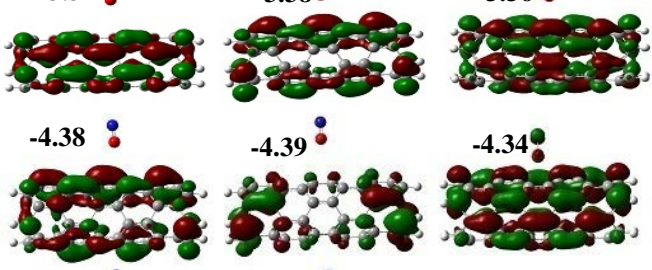

-4.39 :

$-4.34$

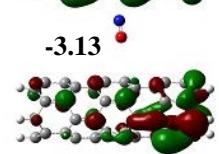
-88 88

$-3.14^{\circ}$

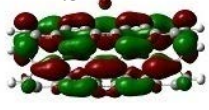

-3.20 :

$\because 0305$
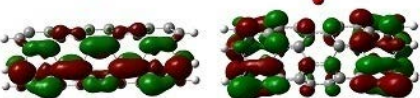

$-4.51 \div$

$-4.57$

$-4.61=$

स: $\frac{1}{3}:$ :

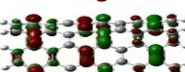

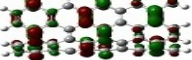

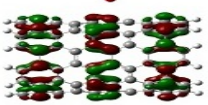

$-2.79$

-2.80 !

$-2.82:-$

ริำ

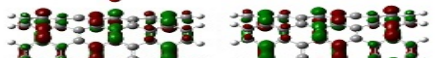

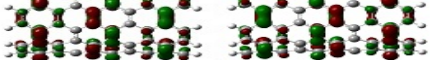

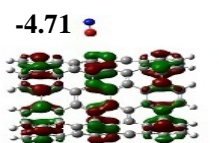

$-2.778$

-4.66 :

$-4.71:$

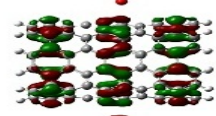

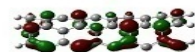

$-2.78$

3.8.838:

\section{$\because 3: 3: 3$}

-2.79 :

궁:3을

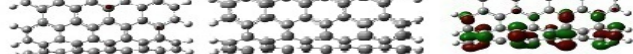

Figure 3. HOMO and LUMO molecular orbitals of adsorbing $\mathrm{NO}$ and $\mathrm{NO}_{2}$ gas molecules on the pristine $(5,0)$, $(9,0)$, $(5,5)$ and $(6,6)$ CNTs. Energies of HOMO and LUMO are listed above their molecular orbitals and are given by $\mathrm{eV}$.

Table 6. The calculated dipole moments of pristine and after adsorbing $\mathrm{CO}$ and $\mathrm{CO}_{2}$ gas molecules above a carbon site, a bond site and a vacant site of $(5,0),(9,0),(5,5)$ and $(6,6)$ CNTs. All dipole moments are given by Debye.

\begin{tabular}{rccccccc}
\hline \multicolumn{1}{c}{} & \multicolumn{3}{c}{$\mathrm{CO}$} \\
\multicolumn{1}{c}{ system } & Pristine CNTs & Carbon site & Bond site & Vacant Site & Carbon Site & Bond Site & Vacant Site \\
\hline$(5,0)$ CNT & 0.54 & 0.54 & 0.56 & 0.49 & 0.46 & 0.47 & 0.62 \\
$(9,0)$ CNT & 0.20 & 0.40 & 0.21 & 0.10 & 0.23 & 0.74 & 0.30 \\
$(5,5)$ CNT & 0.00 & 0.04 & 0.12 & 0.06 & 0.21 & 0.25 & 0.77 \\
$(6,6)$ CNT & 0.00 & 0.06 & 0.05 & 0.06 & 0.23 & 0.23 & 0.26 \\
\hline
\end{tabular}

spectively. Comparing the dipole moments of the pristine CNTs with ones that are adsorbed the $\mathrm{NO}$ and $\mathrm{NO}_{2}$ gas molecules, it is found that the dipole moments are getting higher. When the $\mathrm{NO}$ and $\mathrm{NO}_{2}$ gas molecules are adsorbed on the vacant sites of CNTs, their dipole moments are either quite close to or are lower than the dipole moments of pristine CNTs, except in case of adsorbing $\mathrm{NO}_{2}$ on $(5,0)$ CNT, the dipole moment is increased. Also, all the calculated dipole moments of adsorbing $\mathrm{NO}$ and $\mathrm{NO}_{2}$ gas molecules on the carbon sites of CNTs 
Table 7. The calculated dipole moments of pristine and after adsorbing $\mathrm{NO}$ and $\mathrm{NO}_{2}$ gas molecules above a carbon site, a bond site and a vacant site of $(5,0),(9,0),(5,5)$ and $(6,6)$ CNTs. All dipole moments are given by Debye.

\begin{tabular}{|c|c|c|c|c|c|c|}
\hline \multirow[b]{2}{*}{ system } & \multicolumn{3}{|c|}{ NO } & \multicolumn{3}{|c|}{$\mathrm{NO}_{2}$} \\
\hline & Carbon site & Bond Site & Vacant Site & Carbon Site & Bond Site & Vacant site \\
\hline$(5,0) \quad \mathrm{CNT}$ & 5.58 & 1.12 & 0.36 & 0.28 & 0.97 & 1.47 \\
\hline$(9,0) \quad \mathrm{CNT}$ & 0.46 & 0.48 & 0.11 & 0.69 & 0.11 & 0.07 \\
\hline$(5,5) \quad \mathrm{CNT}$ & 0.14 & 0.11 & 0.11 & 1.48 & 0.58 & 0.13 \\
\hline$(6,6) \quad \mathrm{CNT}$ & 0.15 & 0.31 & 0.17 & 0.20 & 0.53 & 0.17 \\
\hline
\end{tabular}

are increased, except in case of adsorbing $\mathrm{NO}_{2}$ on $(5,0)$ CNT, the dipole moment is decreased. In case of adsorbing $\mathrm{NO}$ and $\mathrm{NO}_{2}$ gas molecules on the bond sites of CNTs the dipole moments are also increased, except in case of adsorbing $\mathrm{NO}_{2}$ on $(9,0)$ CNT is decreased, see Table 7.

From Table 6, Table 7, it is clear that the dipole moments of zig-zag $(5,0)$ and $(9,0)$ CNTs are always higher than the arm-chair $(5,5)$ and $(6,6)$ CNTs. Also, it is noticed that the dipole moment of adsorbing NO gas molecule on the bond site of $(5,0)$ CNT is increased by ten times comparing with the dipole moment of pristine $(5,0) \mathrm{CNT}$.

\section{Conclusion}

The gas sensing behavior of CNTs, considering a range of different nanotube diameters and chiralities, as well as different adsorption sites is reported. The adsorption of $\mathrm{CO}, \mathrm{CO}_{2}, \mathrm{NO}$, and $\mathrm{NO}_{2}$ gas molecules on the $(5,0)$, $(9,0),(5,5)$ and $(6,6)$ CNTs are studied using B3LYP/6-31 g(d, p). Three different adsorption sites (above a carbon site, a bond site and a vacant site) are applied on CNTs. It is found that the adsorption of $\mathrm{CO}$ and $\mathrm{CO}_{2}$ gas molecules is dependent on the chiralities and the diameters of CNTs and it is enhanced with increasing the diameter of the zig-zag CNTs. However, the adsorption of $\mathrm{NO}$ and $\mathrm{NO}_{2}$ gas molecules is independent on the chiralities and the diameters of CNTs. Also, the electronic character of $(5,0),(9,0),(5,5)$ and $(6,6)$ CNTs is not affected by the adsorption of $\mathrm{CO}$ and $\mathrm{CO}_{2}$ gas molecules. While, the adsorption of $\mathrm{NO}$ and $\mathrm{NO}_{2}$ gas molecules on CNTs is only strongly affected by the electronic character of the $(9,0)$ and $(5,0)$ CNTs but the $(5,5)$ and $(6,6)$ CNTs are not affected at all. It is found that the dipole moments of zig-zag $(5,0)$ and $(9,0)$ CNTs are always higher than the arm-chair $(5,5)$ and $(6,6)$ CNTs. Also, it is noticed that the dipole moment of adsorbing NO gas molecule on the bond site of $(5,0)$ CNT is increased by ten times compared with the dipole moment of pristine $(5,0) \mathrm{CNT}$. Therefore, these findings prove that the zig-zag carbon nanotubes are better than the arm-chair carbon nanotubes as gas sensors, especially for $\mathrm{NO}$ and $\mathrm{NO}_{2}$ gas molecules.

\section{References}

[1] Kong, J., Franklin, N.R., Zhou, C., Chapline, M.G., Peng, S. and Cho, K. (2000) Nanotube Molecular Wires as Chemical Sensors. Science, 287, 622. http://dx.doi.org/10.1126/science.287.5453.622

[2] Snow, E.S., Perkins, F.K., Houser, E.J., Badescu, S.C. and Reinecke, T.L. (2005) Chemical Detection with a Single-Walled Carbon Nanotube Capacitor. Science, 307, 1942-1945. http://dx.doi.org/10.1126/science.1109128

[3] Baei, M.T., Soltani, A.R., Moradi, A.V. and Lemeski, E.T. (2011) Adsorption Properties of NO on (6, 0), (7, 0), and (8, 0) Zigzag Single-Walled Boron Nitride Nanotubes: A Computational Study. Computational and Theoretical Chemistry, 970, 30-35. http://dx.doi.org/10.1016/j.comptc.2011.05.021

[4] Breza, M. (2006) Model Studies of $\mathrm{SOCl}_{2}$ Adsorption on Carbon Nanotubes. Journal of Molecular Structure: THEOCHEM, 767, 159-163. http://dx.doi.org/10.1016/j.theochem.2006.06.006

[5] Zhao, J., Buldum, A., Han, J. and Lu, J.P. (2002) Gas Molecule Adsorption in Carbon Nanotubes and Nanotube Bundles. Nanotechnology, 13, 195-200. http://dx.doi.org/10.1088/0957-4484/13/2/312

[6] Ricca, A. and Bauschlicher Jr., C.W. (2006) The Adsorption of NO on (9, 0) and (10, 0) Carbon Nanotubes. Chemical Physics, 323, 511-518. http://dx.doi.org/10.1016/j.chemphys.2005.10.019

[7] Abbas Rafati, A., Majid Hashemianzadeh, S. and Bolboli Nojini, Z. (2008) Electronic Properties of Adsorption Nitrogen Monoxide on Inside and Outside of the Armchair Single Wall Carbon Nanotubes: A Density Functional Theory Calculations. The Journal of Physical Chemistry C, 112, 3597-3604. http://dx.doi.org/10.1021/jp709955g 
[8] Azizi, K., Majid Hashemianzadeh, S. and Bahramifar, Sh. (2011) Density Functional Theory Study of Carbon Monoxide Adsorption on the Inside and Outside of the Armchair Single-Walled Carbon Nanotubes. Current Applied Physics, 11, 776-782. http://dx.doi.org/10.1016/j.cap.2010.11.071

[9] Ricca, A., Bauschlicher Jr., C.W. (2006) The Physisorption of $\mathrm{CH}_{4}$ on Graphite and on a (9, 0) Carbon Nanotube. Chemical Physics, 324, 455-458. http://dx.doi.org/10.1016/j.chemphys.2005.11.010

[10] Santucci, S., Picozzi, S., Di Gregorio, F., Lozzi, L., Cantalini, C., Valentini, L., Kenny, J.M. and Delley, B. (2003) NO 2 and CO Gas Adsorption on Carbon Nanotubes: Experiment and Theory. The Journal of Chemical Physics, 119, 10904-10910. http://dx.doi.org/10.1063/1.1619948

[11] Zanolli, Z. and Charlier, J.C. (2009) Defective Carbon Nanotubes for Single-Molecule Sensing. Physical Review B, 80, 155447. http://dx.doi.org/10.1103/PhysRevB.80.155447

[12] Tang, S. and Cao, Z. (2009) Defect-Induced Chemisorption of Nitrogen Oxides on (10, 0) Single-Walled Carbon Nanotubes: Insights from Density Functional Calculations. The Journal of Chemical Physics, 131, 114706. http://dx.doi.org/10.1063/1.3226572

[13] García-Lastra, J.M., Mowbray, D.J., Thygesen, K.S., Rubio, A. and Jacobsen, K.W. (2010) Modeling Nanoscale Gas Sensors under Realistic Conditions: Computational Screening of Metal-Doped Carbon Nanotubes. Physical Review B, 81, 245429. http://dx.doi.org/10.1103/PhysRevB.81.245429

[14] Denis, P.A. (2008) Methane Adsorption Inside and Outside Pristine and N-Doped Single Wall Carbon Nanotubes. Chemical Physics, 353, 79-86. http://dx.doi.org/10.1016/j.chemphys.2008.07.024

[15] Yeung, C.S., Liu, L.V. and Wang, Y.A. (2008) Adsorption of Small Gas Molecules onto Pt-Doped Single-Walled Carbon Nanotubes. The Journal of Physical Chemistry C, 112, 7401-7411. http://dx.doi.org/10.1021/jp0753981

[16] Zhao, J.X. and Ding, Y.H. (2008) Theoretical Study of the Interactions of Carbon Monoxide with Rh-Decorated (8, 0) Single-Walled Carbon Nanotubes, Materials Chemistry and Physics, 110, 411-416. http://dx.doi.org/10.1016/j.matchemphys.2008.02.036

[17] An, W. and Turner, C.H. (2009) Electronic Structure Calculations of Gas Adsorption on Boron Doped Carbon Nanotubes Sensitized with Tungsten. Chemical Physics, 482, 274-280.

[18] Sayago, I., Santos, H., Horrillo, M.C., Aleixandre, M., Fernández, M.J., Terrado, E., Tacchini, I., Aroz, R., Maser, W.K., Benito, A.M., Martínez, M.T., Gutiérrez, J. and Munoz, E. (2008) Carbon Nanotube Networks as Gas Sensors for $\mathrm{NO}_{2}$ Detection. Talanta, 77, 758-764. http://dx.doi.org/10.1016/j.talanta.2008.07.025

[19] Li, X.M., Tian, W.Q., Dong, Q., Huang, X.R., Sun, C.C. and Jiang, L. (2011) Substitutional Doping of BN Nanotube by Transition Metal: A Density Functional Theory Simulation. Computational and Theoretical Chemistry, 964, 199-206. http://dx.doi.org/10.1016/j.comptc.2010.12.026

[20] Chen, H.L., Wu, S.Y., Chen, H.T., Chang, J.G., Ju, S.P., Tsai, C. and Hsu, L.C. (2010) Theoretical Study on Adsorption and Dissociation of $\mathrm{NO}_{2}$ Molecule on Fe(1 11 1) Surface. Langmuir, 26, 7157-7164. http://dx.doi.org/10.1021/la904233b

[21] Wickham, D.T., Banse, B.A. and Koel, B.E. (1991) Adsorption of Nitrogen Dioxide and Nitric Oxide on Pd(1 11 ). Surface Science, 243, 83-95. http://dx.doi.org/10.1016/0039-6028(91)90347-U

[22] Jirsak, T., Kuhn, M. and Rodriguez, J.A. (2000) Chemistry of $\mathrm{NO}_{2}$ on $\mathrm{Mo}\left(\begin{array}{l}1 \\ 1\end{array}\right.$ 0): Decomposition Reactions and Formation of $\mathrm{MoO}_{2}$. Surface Science, 457, 254-266. http://dx.doi.org/10.1016/S0039-6028(00)00381-2

[23] Huang, W., Jiang, Z., Jiao, J., Tan, D., Zhai, R. and Bao, X. (2002) Decomposition of NO on Pt(1 1 0): Formation of a New Oxygen Adsorption State. Surface Science, 506, 287-292. http://dx.doi.org/10.1016/S0039-6028(02)01381-X

[24] Hellman, A., Panas, I. and Grönbeck, H. (2008) $\mathrm{NO}_{2}$ Dissociation on $\operatorname{Ag}\left(\begin{array}{lll}1 & 1 & 1\end{array}\right)$ Revisited by Theory. Journal of Chemical Physics, 128, 104704-104709. http://dx.doi.org/10.1063/1.2832303

[25] Yen, M.Y. and Ho, J.J. (2010) Density-Functional Study for the $\mathrm{NO}_{\mathrm{x}}(\mathrm{x}=1,2)$ Dissociation Mechanism on the Cu(1 1 1) Surface. Chemical Physics, 373, 300-306. http://dx.doi.org/10.1016/j.chemphys.2010.06.005

[26] Frisch, M.J., Trucks, G.W., Schlegel, H.B., Scuseria, G.E., Robb, M.A., Cheeseman, J.R., Zakrzewski, V.G., Montgomery, J.A., Stratmann, R.E., Burant, J.C., Dapprich, S., Millam, J.M., Daniels, A.D., Kudin, K.N., Strain, M.C., Farkas, O., Tomasi, J., Barone, V., Cossi, M., Cammi, R., Mennucci, B., Pomelli, C., Adamo, C., Clifford, S., Ochterski, J., Petersson, G.A., Ayala, P.Y., Cui, Q., Morokuma, K., Malick, D.K., Rabuck, A.D., Raghavachari, K., Foresman, J.B., Cioslowski, J., Ortiz, J.V., Stefanov, B.B., Liu, G., Liashenko, A., Piskorz, P., Komaromi, I., Gomperts, R., Martin, R.L., Fox, D.J., Keith, T., Al-Lamham, M.A., Peng, C.Y., Nanayakkara, A., Gonzalez, C., Challacombe, M., Gill, P.M.W., Johnson, B.G., Chen, W., Wong, M.W., Andres, J.L., Head-Gordon, M., Replogle, E.S. and Pople, J.A. (2004) Gaussian. Wallingford CT, Inc., Wallingford.

[27] EL-Barbary, A.A., Lebda, H.I. and Kamel, M.A. (2009) The High Conductivity of Defect Fullerene C $_{40}$ Cage. Computational Materials Science, 46, 128. http://dx.doi.org/10.1016/j.commatsci.2009.02.034 
[28] El-Barbary, A.A., Eid, K.M., Kamel, M.A. and Hassan, M.M. (2013) Band Gap Engineering in Short Heteronanotube Segments via Monovacancy Defects. Computational Materials Science, 69, 87-94. http://dx.doi.org/10.1016/j.commatsci.2012.10.035

[29] EL-Barbary, A.A., Ismail, G.H. and Babeer, A.M. (2013) Effect of Monovacancy Defects on Adsorbing of $\mathrm{CO} \mathrm{CO}_{2}$, $\mathrm{NO}$ and $\mathrm{NO}_{2}$ on Carbon Nanotubes: First Principle Calculations. Journal of Surface Engineered Materials and Advanced Technology, 3, 287-294. http://dx.doi.org/10.4236/jsemat.2013.34039

[30] Nalwa, H. (2002) Nanostructured Materials and Nanotechnology. Academic Press, San Diego.

[31] Chang, H., Lee, J.D., Lee, S.M. and Lee, Y.H. (2001) Adsorption of $\mathrm{NH}_{3}$ and $\mathrm{NO}_{2}$ Molecules on Carbon Nanotubes. Applied Physics Letters, 79, 3863. http://dx.doi.org/10.1063/1.1424069 